\title{
Herpes Simplex Viruses: Mechanisms of DNA Replication
}

\author{
Sandra K. Weller ${ }^{1}$ and Donald M. Coen ${ }^{2}$ \\ ${ }^{1}$ Department of Molecular, Microbial and Structural Biology, University of Connecticut Health Center, \\ Farmington, Connecticut 06030-3205 \\ ${ }^{2}$ Department of Biological Chemistry and Molecular Pharmacology, Harvard Medical School, Boston, \\ Massachusetts 02115 \\ Correspondence: weller@nso2.uchc.edu
}

\begin{abstract}
Herpes simplex virus (HSV) encodes seven proteins necessary for viral DNA synthesis-UL9 (origin-binding protein), ICP8 (single-strand DNA [ssDNA]-binding protein), UL30/UL42 (polymerase), and UL5/UL8/UL52 (helicase/primase). It is our intention to provide an upto-date analysis of our understanding of the structures of these replication proteins and how they function during HSV replication. The potential roles of host repair and recombination proteins will also be discussed.
\end{abstract}

$T_{b}^{\text {h }}$ he Herpesviridae are a large family of double-stranded DNA viruses responsible for many human and veterinary diseases. Although members of this family differ in tissue tropism and many aspects of their interactions with their hosts, the mechanisms by which they replicate their DNA during productive ("lytic") infection are largely conserved. The molecular mechanisms involved in herpesvirus DNA replication and its regulation are of interest as they provide important models for the study of eukaryotic DNA replication. Many of the replication proteins encoded by herpesviruses represent functional analogs of the eukaryotic DNA replication machinery, with informative similarities and differences. In addition, viral enzymes involved in DNA replication have provided a rich store of useful targets for antiviral therapy. This work will focus primarily on DNA replication of herpes simplex virus 1 and
2 (HSV-1 and HSV-2), but will refer, on occasion, to findings from other herpesviruses. Because this work is intended to update the work on HSV DNA replication written for the previous edition of DNA Replication and Human Disease (Weller and Coen 2006), it draws primarily from work published during the last 6 years. Topics covered in detail in the previous work by the authors (Weller and Coen 2006) and reviewed elsewhere will be summarized only briefly (see Coen 2009; Weller 2010; Livingston and Kyratsous 2011; Ward and Weller 2011; Weitzman and Weller 2011).

\section{HSV-1 GENOME AND ORIGINS OF DNA REPLICATION}

The HSV genome is large (152 kbp) and structurally complex, consisting of two unique regions (UL and US) flanked by inverted repeat

Editors: Stephen D. Bell, Marcel Mechali, and Melvin L. DePamphilis

Additional Perspectives on DNA Replication available at www.cshperspectives.org

Copyright (C) 2012 Cold Spring Harbor Laboratory Press; all rights reserved; doi: 10.1101/cshperspect.a013011

Cite this article as Cold Spring Harb Perspect Biol 2012;4:a013011 
sequences arranged as ab-UL- $b^{\prime} a^{\prime} c^{\prime}$-US-ca (reviewed in Ward and Weller 2011, and references therein). The HSV genome contains three origins of replication: OriS is present twice in the viral genome in the repeated $\mathrm{c}$ region and OriL is present in UL. Both OriL and OriS are located in the promoter-regulatory regions of divergently transcribed genes: OriL between genes encoding replication proteins, ICP8 (UL29) and the catalytic subunit of the polymerase (Pol) and OriS between genes encoding immediate early proteins ICP4 and either ICP22 or ICP47. OriL and OriS contain an A/T-rich region surrounded by recognition sites for the origin-binding protein (OBP), UL9. OriS contains a 45-bp imperfect palindrome in which the $\mathrm{A} / \mathrm{T}$-rich region is flanked by two recognition sites for the OBP (box I and box II) (see Fig. 1 from Ward and Weller 2011). A third weaker binding site (box III) is located adjacent to box I. Box I and box III are located on opposite strands and have been reported to adopt an unusual hairpin structure on single-strand (ssDNA) (OriS*) (Aslani et al. 2002). HSV OriL contains a 144-bp perfect palindrome that includes four recognition sites for UL9 such that hairpins could theoretically form on both sides of the AT-rich region in OriL. A recent report suggests that the varicella zoster virus (VZV) genome also contains two copies of OriS and that, as in HSV-1 and HSV-2, each OriS contains three origin-binding sites (Khalil et al. 2011). The configuration, however, differs in that the OBP binding sites are all on the same strand and oriented in the same direction, suggesting that the hairpin structure that can form in HSV OriS cannot form in the VZV version. Although HSV-1 mutants lacking one or two origins are competent for lytic replication in cell culture (Polvino-Bodnar et al. 1987; Igarashi et al. 1993), the in vivo behavior of mutant viruses containing point mutations in site I of OriL or OriS may indicate that OriL plays a role in in vivo replication or pathogenesis (Balliet and Schaffer 2006). Interestingly it appears that both OriL and OriS encode micro RNAs (miRNAs) (Jurak et al. 2010), so it cannot be excluded that the mutations in OriL that alter pathogenicity exert their influence through these miRNAs.

\section{TRANS-ACTING PROTEINS: ESSENTIAL REPLICATION PROTEINS}

HSV encodes seven essential replication proteins (Table 1). Six of these play "core" replication roles at the replication fork and are conserved in all known herpesviruses: a single-strand DNAbinding protein (known as ICP8 or UL29), a two-subunit DNA polymerase (catalytic subunit Pol and processivity subunit UL42), and a threesubunit helicase/primase complex (H/P:UL5, UL8, and UL52) (reviewed in Ward and Weller 2011). In addition to the core replication proteins, HSV-1 and HSV-2 also encode an originbinding protein (UL9). The origins of replication in $\beta$ and $\gamma$ herpesviruses are more complex, and no clear UL9 homologs have been identified. Thus, although the overall strategy of lytic viral DNA replication appears to be conserved in all herpesviruses, the mechanism and regulation of initiation of viral DNA synthesis may differ among the three herpesvirus subfamilies.

\section{ICP8, THE MAJOR ssDNA-BINDING PROTEIN (UL29)}

ICP8, encoded by the UL29 gene, originally identified as the major HSV single-strand DNA-binding protein (SSB) is believed to play a role in viral DNA synthesis, control of viral gene expression, the formation of prereplicative sites and replication compartments, and in the high level of recombination shown during HSV infection (as reviewed in Weller and Coen 2006; Ward and Weller 2011). This multifunctional $130-\mathrm{kDa}$ zinc metalloprotein preferentially binds ssDNA in a nonsequence-specific and cooperative manner and shows helix-destabilizing activities that are consistent with a role in DNA synthesis. ICP8 has been reported to contact many viral and cellular proteins to carry out its multiple functions. Viral interaction partners include UL9, HSV polymerase, helicase/primase $(\mathrm{H} / \mathrm{P})$, UL12, ICP4, and ICP27 (reviewed in Chattopadhyay et al. 2006; Weller and Coen 2006; Ward and Weller 2011). Many of these interactions result in stimulation of activities reviewed below. Putative cellular interaction partners are discussed below. 
Herpes Simplex Viruses
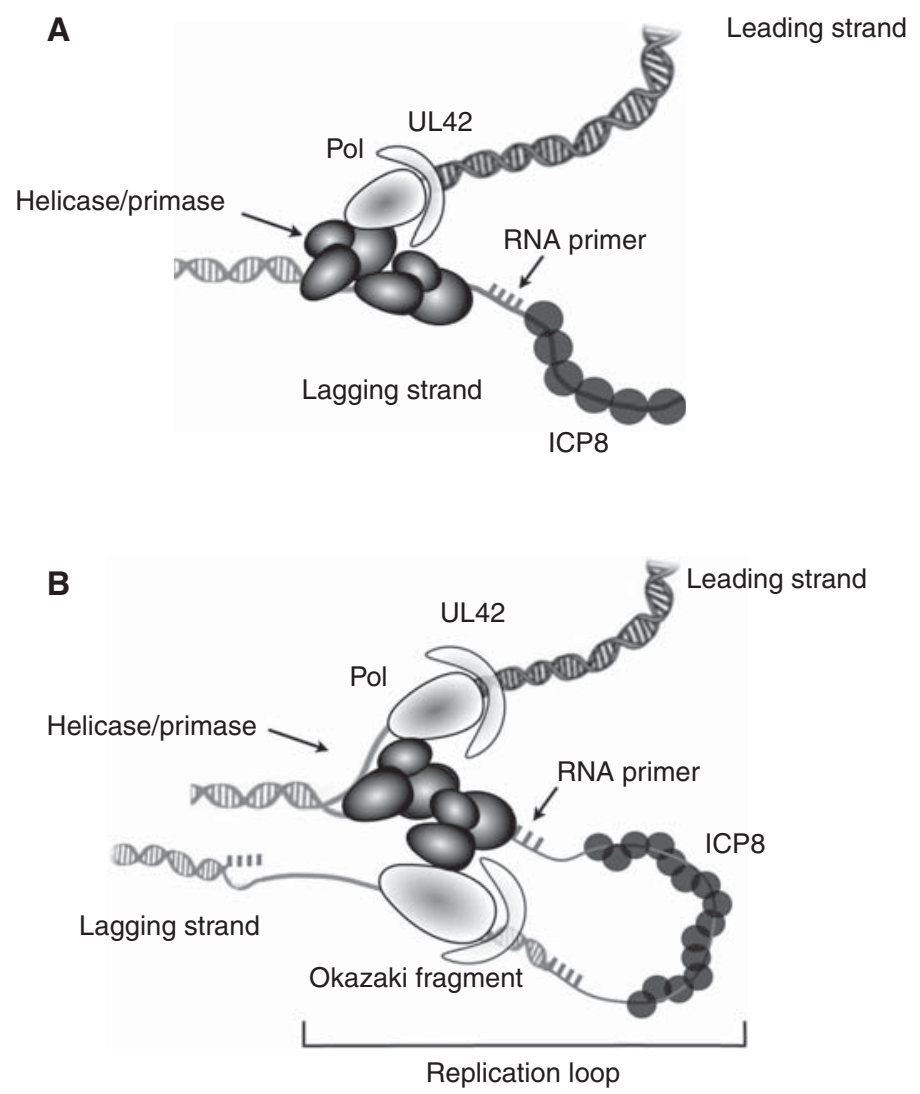

Figure 1. Organization of the HSV-1 replication fork. (A) Herpes simplex virus (HSV) replication fork. Two heterotrimeric complexes of the helicase-primase $(\mathrm{H} / \mathrm{P})$ (dark gray spheres with white centers) are shown at the replication fork. This model is based on a recent report that to achieve efficient primase activity at a forked substrate, two (or more) heterotrimers of the helicase-primase complex are required (Chen et al. 2011). In this diagram, a duplex DNA molecule is unwound by one molecule of $\mathrm{H} / \mathrm{P}$. The HSV polymerase (white shapes with gray centers in which UL30 is shown as an oval and UL42 as a crescent) performs leading-strand DNA synthesis on the top strand. On the bottom strand the second molecule of $\mathrm{H} / \mathrm{P}$ is shown laying down an RNA primer depicted as hatched bars. The single-strand DNA (ssDNA) extruded behind the helicase is coated by the ssDNAbinding protein ICP8 (uniformly dark gray circles). (B) Coupled leading- and lagging-strand synthesis. Coupled leading- and lagging-strand DNA synthesis was recently reconstituted in vitro and requires HSV polymerase, helicase-primase, and ICP8 (Stengel and Kuchta 2011). In this model, coupled leading- and lagging-strand DNA synthesis requires two heterotrimers of helicase/primase and two molecules of the DNA polymerase. The leading- and lagging-strand polymerase molecules are proposed to communicate with each other mediated by interactions between UL30 and the UL5 and UL8 subunits of the H/P (reviewed in the text). A replication loop is formed in the lagging strand to align it with the leading strand. The lagging-strand DNA polymerase initiates Okazaki fragment synthesis using RNA primers (hatched bars).

The structure of ICP8 lacking its carboxyterminal 60 residues was published in 2005 (Mapelli et al. 2005) and details were reviewed in Weller and Coen (2006) and Ward and Weller (2011). Purified ICP8 forms dimers and higherorder filaments in vitro and when bound to
ssDNA holds the DNA in an extended conformation (Mapelli et al. 2000, 2005; Makhov et al. 2009). Recent three-dimensional (3D) reconstruction of an ICP8-ssDNA complex sheds light on the role of ICP8 as a single-strand annealing protein (SSAP) (G Tolun, AM Makhov, 
SJ Ludtke, et al., in prep.). Fitting the crystal structure into this $3 \mathrm{D}$ reconstruction allows predictions concerning the mechanism of ICP8driven annealing.

\section{Pol/UL42, the DNA Polymerase}

The crystal structure of HSV Pol reveals that this enzyme contains structural domains typical of most polymerases including thumb, palm, and fingers, along with a $3^{\prime}-5^{\prime}$ exonuclease domain similar to those of other $\alpha$-like DNA polymerases. However, the structure revealed two other domains: a pre- $\mathrm{NH}_{2}$-terminal domain (1-140) and an $\mathrm{NH}_{2}$-terminal domain defined by Liu et al. (2006) as residues $141-362$ and 594639. The pre- $\mathrm{NH}_{2}$-terminal domain is conserved among herpesvirus, but not other $\alpha$ like DNA polymerases. A conserved motif in this domain is not important for DNA polymerase activity, but is important for viral DNA synthesis in infected cells (S Terrell and DM Coen, submitted). The $\mathrm{NH}_{2}$-terminal domain contains some structures and motifs found in herpesvirus and certain other $\alpha$-like DNA polymerases. The more amino-terminal segment of this domain resembles certain RNA-binding proteins, leading to the revival of the idea that HSV Pol contains a $5^{\prime}-3^{\prime}$ RNase $\mathrm{H}$ activity important for removal of primers (Liu et al. 2006). On the other hand, although HSV Pol has RNase $\mathrm{H}$ activity, it is not clear if this activity is separate from the $3^{\prime}-5^{\prime}$ exonuclease activity (reviewed in Coen 1996). Additionally, the cellular protein, flap endonuclease-1 (Fen-1) can cooperate with HSV Pol to remove primers from model lagging-strand intermediates in vitro, whereas these primers were not removed by Pol alone (Zhu et al. 2010). An alternative role for the amino-terminal domain - that it has a role in displacement of RNA primers for degradation by Fen-1 - was proposed in a paper describing the structure of yeast DNA polymerase $\delta$ (Swan et al. 2009).

Unexpectedly, HSV Pol contains apurinic/ apyrmidinic and $5^{\prime}$-deoxyribose phosphate lyase activities, normally associated with repair polymerases (Bogani and Boehmer 2008). The DNA lyase activity active site appears to reside somewhere in the thumb, palm, or fingers domains (Bogani and Boehmer 2008). HSV Pol also binds to the HSV uracil-DNA-glycosylase, UL2 (Bogani et al. 2010). UL2 binding does not require the extreme carboxyl terminus of Pol (Bogani et al. 2010). A similar result was obtained with the human cytomegalovirus (HCMV) homologs of these proteins (Strang et al. 2010a). UL2 is not required for viral replication (Mullaney et al. 1989; Pyles and Thompson 1994) raising the possibility that this protein-protein interaction is important for coordinating DNA synthesis and repair.

HSV Pol has also been reported to interact with cellular proteins. Pol appears to be a "client" of heat shock protein (Hsp) 90 (Burch and Weller 2005). Pol can interact with the transcriptional coactivator HCF-1 in yeast two-hybrid and transfection-coimmunoprecipitation assays. HCF-1 can interact with the histone chaperone Asf1b in similar assays, and Asflb is important for viral DNA replication (Peng et al. 2010). Whether these interactions occur during HSV infection remains under investigation.

As previously reviewed (Weller and Coen 2006), UL42 closely resembles a monomer of the "sliding clamp" processivity factor, PCNA. Interestingly, the related proteins of $\beta$ and $\gamma$ herpesviruses form head-to-head dimers that partially encircle DNA (Appleton et al. 2004, 2006; Komazin-Meredith et al. 2008b; Baltz et al. 2009; Murayama et al. 2009). One surface of UL42 binds to Pol, whereas the other surface mediates DNA binding (Randell et al. 2005; Komazin-Meredith et al. 2008c) and is important for viral replication, DNA synthesis, and replication fidelity (Jiang et al. 2007a,b). Too tight binding to DNA reduces viral replication and replication fidelity (Jiang et al. 2009). UL42 can diffuse rapidly on DNA, with diffusion coefficients approaching $2 \times 10^{5} \mathrm{bp}^{2} / \mathrm{sec}$ (Komazin-Meredith et al. 2008a). Remarkably, unlike PCNA (Kochaniak et al. 2009), UL42 does not "slide" on DNA. Rather, it hops; i.e., it microscopically dissociates from DNA and then reassociates with either the same stretch of DNA or an adjacent stretch (Komazin-Meredith et al. 2008a). Thus, UL42 promotes processivity by tethering UL30 to DNA through direct DNA 
binding, and diffuses on DNA behind UL30 as it synthesizes long DNA chains.

Like PCNA (Maga and Hubscher 2003; Moldovan et al. 2007), herpesvirus processivity subunits interact with multiple proteins. Aside from previously described interactions (reviewed in Weller and Coen 2006), UL42 coimmunoprecipitates with Fen-1 from HSV-infected cells (Zhu et al. 2010). The HCMV homolog of UL42 (UL44) coimmunoprecipitates with a variety of viral and cellular proteins, including, surprisingly, the nucleolar protein nucleolin, which was found to be important for maintenance of replication compartment architecture and viral DNA synthesis (Gao et al. 2008; Kim and Ahn 2010; Strang and Coen 2010; Strang et al. 2010a,b, 2012).

\section{HELICASE/PRIMASE (UL5/UL8/UL52)}

The HSV-1 helicase/primase $(\mathrm{H} / \mathrm{P})$ is a heterotrimer consisting of the products of the UL5, UL8, and UL52 genes (reviewed in Chattopadhyay et al. 2006; Ward and Weller 2011). A subcomplex of UL5 and UL52 shows DNA-dependent ATPase, primase, and helicase activities, and UL8 interacts with other components of the replication machinery possibly functioning to coordinate replication fork progress. The relationship between UL5 and UL52 reflects a complex interdependence between these two subunits. For instance, mutations in the putative zinc finger at the carboxyl terminus of UL52 abrogate not only primase but also ATPase, helicase, and DNA-binding activities of the UL5/ UL52 subcomplex (Chen et al. 2005; Cavanaugh and Kuchta 2009; Cavanaugh et al. 2009). Unlike all other replicative helicases that form hexameric rings around ssDNA, the $\mathrm{HSV} \mathrm{H} / \mathrm{P}$ is unlikely to form a hexamer. UL5 is a member of the SF1 helicase superfamily generally thought to exist as monomers in solution. The $\mathrm{HSV} \mathrm{H} / \mathrm{P}$ behaves as a single heterotrimer by gel filtration (Dodson and Lehman 1991); however, as described below, two or more $\mathrm{H} / \mathrm{P}$ heterotrimers are needed on partially double-stranded DNA substrates to observe efficient primase activity (Fig. 1A) (Chen et al. 2011). This apparent DNA-dependent multimerization is reminis- cent of the behavior of other SF1 family helicases, which show unwinding of double-stranded DNA (dsDNA) only if at least two helicase polypeptides are present (Maluf et al. 2003; Niedziela-Majka et al. 2007; Yang et al. 2008). Direct protein-protein interactions between the helicase protomers appear unnecessary to achieve enhanced unwinding. By analogy with other SF1 family members, it is possible that two HSV heterotrimeric complexes bind at the replication fork even if there is no direct contact between them and that the presence of two or more complexes enhances the processivity of the $\mathrm{H} / \mathrm{P}$ complex.

\section{UL9, OBP}

UL9, the HSV OBP, forms a dimer in solution and shows several biochemical activities including nucleoside triphosphatase, DNA helicase on partially double-stranded substrates, nonspecific ssDNA binding, and cooperative binding at an origin of replication reviewed in Ward and Weller (2011). Seven conserved helicase motifs characteristic of the SF2 family of helicases reside in the amino-terminal domain of UL9 (between residues 1-534) and are essential both in vivo and for the in vitro ATPase and helicase activities reviewed in Ward and Weller (2011). The domain responsible for specific origin binding (at repeated GTTCGCAC sites) lies within the carboxyl terminus of UL9 (residues 564-832). More specifically, a conserved sequence element in UL9, RVKNL (amino acids 756-760), was recently shown to be required for origin-specific DNA binding (Olsson et al. 2009). Interestingly, residues in other regions of the UL9 protein are capable of modulating origin-specific DNA-binding activity of UL9 (Chattopadhyay and Weller 2006, 2007; Olsson et al. 2009). Although the carboxyl terminus of UL9 can bind origin DNA with a similar footprint to that of full-length UL9, it cannot induce the A/T-rich distorted structure seen with fulllength UL9 suggesting that sequences important for cooperativity reside in the amino terminus (reviewed in Ward and Weller 2011). Based on these observations, it had been assumed that the amino-terminal 534 residues contain a 
region necessary for efficient dimerization and that UL9 dimers adopt a head-to-head configuration. However, UL9 dimers may be oriented in a head-to-tail arrangement in which the amino terminus is in contact with the carboxyl terminus (Chattopadhyay and Weller 2007). Electron microscopy (EM) studies of UL9 bound to oriS suggest the existence of a pair of dimers assembled on oriS (Makhov et al. 1996). It has been proposed that one subunit of the dimer contacts a pentanucleotide repeat of the UL9 recognition site in the major groove of one strand, whereas the other subunit contacts the partially overlapping pentanucleotide site on the other strand (Aslani et al. 2002; Macao et al. 2004).

In addition to binding and unwinding duplex DNA at the origins of replication, UL9 has been reported to interact with other viral and cellular proteins. For instance, UL9 has been reported to interact with ICP8, UL8, and UL42 (reviewed in Ward and Weller 2011). ICP8 has been reported to stimulate the helicase and ATPase activities of UL9, and a 13-amino acid sequence (WPXXXGAXXFXXL) in the extreme carboxyl terminus of UL9 has been shown to be responsible for this interaction (Olsson et al. 2009). UL42 has also been reported to enhance the $3^{\prime}$-to- $5^{\prime}$ helicase activity of UL9; however, the functional significance of the UL9-UL8 interaction has not been explored. In addition, although several cellular proteins have been reported to interact with UL9 including the large subunit of DNA polymerase $\alpha$, human neural F-box $42-\mathrm{kDa}$ protein (NFB42 or FBX2), and some heat shock proteins (reviewed in Ward and Weller 2011), it is not clear whether these interactions are required in the context of HSV infection.

\section{Auxiliary Factors Not Essential for Viral DNA Replication}

The HSV-1 genome encodes at least six proteins that play a nonessential auxiliary role in viral DNA synthesis (Table 1). These include several enzymes involved in nucleotide biosynthesis and DNA metabolism: thymidine kinase, ribonucleotide reductase, deoxyuridine triphosphatase, and uracil-DNA-glycolsylase (Table 1). Thymidine kinase is well conserved in the $\alpha$ and $\gamma$ herpesviruses and functions to phosphorylate thymidine and other nucleosides including antiviral compounds such as acyclovir. Viral thymidine kinase (TK) is not required for viral growth in cell culture or in certain tissues in

Table 1. HSV DNA replication genes

\begin{tabular}{|c|c|c|c|}
\hline Gene & $\begin{array}{c}\text { Alternate } \\
\text { abbreviation }\end{array}$ & Major function & $\begin{array}{c}\text { Essential for } \\
\text { DNA synthesis in } \\
\text { cultured cells }\end{array}$ \\
\hline UL9 & OBP & Origin-binding protein, helicase & Yes \\
\hline UL30 & Pol & Catalytic subunit of DNA polymerase & Yes \\
\hline UL42 & & Processivity subunit of DNA polymerase & Yes \\
\hline UL5 & & Subunit of helicase/primase; contains helicase motifs & Yes \\
\hline UL8 & & Subunit of helicase/primase; interacts with other proteins & Yes \\
\hline UL52 & & Subunit of helicase/primase; contains primase motifs & Yes \\
\hline UL29 & ICP8 & $\begin{array}{l}\text { Single-strand DNA-binding protein } \\
\text { Single-strand annealing protein }\end{array}$ & Yes \\
\hline UL23 & TK & Thymidine kinase & No \\
\hline UL39 & RR1, ICP6 & Large subunit of ribonucleotide reductase & No \\
\hline UL40 & RR2 & Small subunit of ribonucleotide reductase & No \\
\hline UL2 & UNG & Uracil-DNA glycosylase & No \\
\hline UL50 & dUTPase & Deoxyuridine triphosphatase & No \\
\hline UL12 & $5^{\prime}-3^{\prime}$ Exo & $\begin{array}{l}\text { Alkaline nuclease; interacts with ICP } 8 \\
\text { Viral recombinase }\end{array}$ & No \\
\hline
\end{tabular}


vivo. Ribonucleotide reductase functions to generate deoxyribonucleotides important for DNA synthesis and consists of two subunits, RR1 and RR2, both of which are needed for enzymatic activity. In addition to the established role for RR1 as the catalytic subunit of ribonucleotide reductase responsible for generating deoxyribonucleotides, the RR1 subunit (also known as ICP6) has been shown to show other activities. For instance the RR1 subunit from both HSV-1 and HSV-2 has been shown to protect cells against apoptosis by interacting with caspase 8 receptor-interacting protein 1 (RIP1) thus interfering with apoptotic host defense mechanisms (Chabaud et al. 2007; Dufour et al. 2010). Moreover, RR1 appears to show chaperone activity similar to that of small heat shock proteins (Chabaud et al. 2003). Lastly, HSV-1 RR1 promotes the assembly of the translational initiation machinery suggesting that ICP6 can function as an eIF4F-assembly chaperone (Walsh and Mohr 2006). These observations underscore the complex evolution of viral proteins such that they are capable of multiple roles during infection.

Other auxiliary functions encoded by HSV1 include the deoxyuridine triphosphatase (dUTPase) and uracil-DNA-glycosylase (UL2), which are not required for viral growth in cell culture but appear to show more severe defects in nondividing cells and in vivo (reviewed in Ward and Weller 2011). The recently reported interaction between the HSV-1 UL2 and Pol described above may indicate a possible role for base excision repair during DNA replication (Bogani et al. 2010).

The HSV alkaline nuclease (UL12) is unusual in that it is not required for viral DNA synthesis per se but is essential for the production of infectious virus. Thus, although newly synthesized viral DNA can be detected in cells infected with HSV-1 mutants defective in UL12, its structure is aberrant leading to defects in packaging. UL12 is well conserved in all herpesvirus genomes and evolutionarily related to a larger family of $5^{\prime}-3^{\prime}$ exonucleases that play important roles in DNA viruses of bacterial, fungi, mammals, and insects. UL12 interacts with HSV ICP8 as well as several components of the host DNA repair machinery (Balasubramanian et al. 2010). Possible roles of UL12 in the virus life cycle will be discussed below.

\section{OVERALL MODEL FOR HSV DNA REPLICATION}

\section{Initiation of Viral DNA Synthesis}

HSV DNA synthesis is believed to initiate at one of the three viral origins of replication, OriL or one of the two copies of OriS with UL9 and ICP8 acting to distort the AT-rich origin spacer region. Complexes containing ICP8 and UL9 can be visualized on negatively supercoiled plasmids containing OriS (Makhov et al. 2003) suggesting that negative supercoiling may facilitate unwinding at the origin. In another in vitro experiment, UL9 and ICP8 were found to unwind an 80-bp double-stranded oligonucleotide containing minimal OriS leading to a model in which UL9 and ICP8 go through a series of conformational changes leading to distortion of an origin. In the first step, two UL9 dimers appear to bind cooperatively to boxes I and II; in a second step, UL9, in conjunction with ICP8 in the presence of ATP, can induce the formation of the OriS* hairpin (Aslani et al. 2002; Macao et al. 2004; Olsson et al. 2009). This step is accompanied by conformational changes in UL9 that shift the binding specificity from duplex origin binding to nonspecific ssDNA binding (Macao et al. 2004; Olsson et al. 2009). Because origin binding is specified by the carboxyl terminus and the ssDNA-binding domain requires motif Ia within the amino terminus (Marintcheva and Weller 2003b), the conformational changes in UL9 would be major. The exposure of single-stranded DNA may also cause a conformational change in ICP8 that releases it from UL9 and positions it onto singlestranded DNA where it may act to prevent reannealing of complementary strands. Aspects of this model have been supported by a biophysical analysis of the carboxy-terminal domain of UL9 and a truncated version of ICP8 in complex with a 15-mer double-stranded DNA-containing box I (Manolaridis et al. 2009). This study suggests that a conformational switch of the 
UL9-binding domain occurs on binding to box I followed by the recruitment of a UL9-ICP8 complex. Several questions remain about how well these in vitro experiments mimic the conditions that arise in an infected cell. Other viral or cellular factors may be required for origin activation on the viral genome in the context of viral infection.

Experiments in infected cells also support the notion that conformational changes in UL9 play critical roles during infection. For instance, UL9 is required at the earliest times postinfection, but appears not to be required at late times. In fact, at late times, UL9 is inhibitory (reviewed in Ward and Weller 2011). The inhibitory properties of UL9 correlate at least in part with its ability to bind to the origins of replication, because inhibition can be relieved by $\mathrm{mu}$ tations that abrogate DNA binding (Marintcheva and Weller 2003a; Chattopadhyay and Weller 2006). Binding of UL9 to the origin of replication is presumably desirable to initiate DNA synthesis but less desirable at later times. Conformational changes in UL9 may be caused by interaction with viral proteins such as ICP8 as described above. Interestingly, other posttranslational modifications of UL9 have also been reported such as phosphorylation and cleavage by cathepsins (Isler and Schaffer 2001; Link et al. 2007). It will be of interest to analyze structural and conformational properties of full-length and truncated versions of UL9 in infected cells to determine the mechanistic basis for the regulation of UL9 during infection.

\section{Elongation}

Once ICP8 and UL9 have initiated the distortion or destabilization at a viral origin as described above, it is thought that the $\mathrm{H} / \mathrm{P}$ complex is recruited to unwind the duplex DNA and synthesize short RNA primers to initiate DNA replication (Fig. 1A). Aspects of this reaction can be reconstituted in vitro. Recombinant $\mathrm{H} / \mathrm{P}$ complex can unwind duplex DNA but only if a single-stranded region of at least six nucleotides is provided (Chen et al. 2011). Primase activity can be detected in assays that use a single-strand ol- igonucleotide as a substrate; however, primase activity is inefficient in assays using forked substrates (KL Graves-Woodward and SK Weller, unpubl.; KA Ramirez-Aguilar and RD Kuchta, unpubl.). A possible reason for this discrepancy has recently been revealed. Although it has previously been reported that in the absence of $\mathrm{DNA}$, the $\mathrm{H} / \mathrm{P}$ complex exists as a monomer in solution, electrophoretic shift and surface plasmon resonance analysis have now indicated that in the presence of forked DNA, higher-order complexes can form between the $\mathrm{H} / \mathrm{P}$ and a forked substrate (Chen et al. 2011). Electrophoretic mobility shift assays reveal two discrete complexes with different mobilities only when $\mathrm{H} / \mathrm{P}$ is bound to DNA containing a singlestranded region, and surface plasmon resonance analysis confirms larger amounts of the complex bound to forked substrates than to single-overhang substrates. In addition, primase activity shows a cooperative dependence on protein concentration, whereas ATPase and helicase activities do not (Chen et al. 2011). Taken together, these data suggest that the primase activity of the $\mathrm{H} / \mathrm{P}$ requires formation of a dimer or higherorder structure, whereas ATPase activity does not. As depicted in Figure 1A, the functional form of the $\mathrm{H} / \mathrm{P}$ complex likely contains at least two copies of the $\mathrm{H} / \mathrm{P}$ complex.

The last of the herpes replication proteins recruited to the fork appears to be the twosubunit polymerase, Pol and UL42. In infected cells, recruitment of Pol requires the presence of an active primase, indicating that conformational changes that occur in an active $\mathrm{H} / \mathrm{P}$ complex and/or the RNA primer itself are important to bring the polymerase to viral DNA (Carrington-Lawrence and Weller 2003). Recruitment of polymerase to the fork may involve direct interactions between Pol and the $\mathrm{H} / \mathrm{P}$. The UL8 subunit of $\mathrm{H} / \mathrm{P}$ has been reported to interact with Pol (Marsden et al. 1996). In addition, the UL5 subunit has recently been found to interact with Pol based on coimmunoprecipitation and yeast two-hybrid analysis (P Bai, G Liu, J Liu, et al., in prep.). Once the polymerase complex is recruited to the replication fork, it is believed to catalyze leading- and lagging-strand DNA synthesis; however, initial 
attempts to reconstitute HSV DNA synthesis on primed substrates showed efficient leading-strand synthesis but much less efficient lagging-strand synthesis (Graves-Woodward et al. 1997; Falkenberg et al. 2000). Coupled leadingand lagging-strand DNA synthesis has now for the first time been reconstituted on synthetic minicircular DNA templates with the $\mathrm{H} / \mathrm{P}$, ICP8, and the viral polymerase (Pol/UL42) (Stengel and Kuchta 2011). To achieve efficient leading- and lagging-strand synthesis, it was necessary to provide high $\mathrm{H} / \mathrm{P}$ concentrations and a lagging-strand template whose sequence resembled that of the viral DNA (Stengel and Kuchta 2011). The presence of two H/P complexes at the replication fork may provide a simple mechanism for recruiting two polymerases to the replication fork (Fig. 1B). It is anticipated that this system will facilitate future experiments to examine how other viral and cellular proteins will affect DNA synthesis. It is hoped that eventually it will be possible to develop a system to reconstitute origin-dependent replication.

\section{Formation of Concatemeric DNA}

Production of HSV concatemeric DNA is an essential step for the generation of progeny virus as the packaging machinery must recognize longer-than-unit-length concatemers during encapsidation. Although it has been proposed that the viral genome circularizes and rolling circle replication leads to the formation of concatemers, several lines of evidence suggest that HSV DNA replication is more complex and may involve recombination-dependent replication.

By analogy with $\lambda$ phage, HSV may use viral and/or cellular recombination proteins during DNA replication. Herpesviruses have evolved a complex relationship with host DNA damage response pathways (reviewed in Weitzman and Weller 2011). Several cellular factors involved in double-strand-break (DSB) repair including Mre11, Rad50, Nbs1, and Rad51 are recruited to viral prereplicative sites and replication compartments. Several of these are important for efficient virus production leading to the suggestion that one or more of the DSB repair pathways may be used during HSV infection. Using chromosomally integrated reporter assays designed to distinguish between these pathways, it was found that single-strand annealing (SSA) was increased in HSV-infected cells, whereas homologous recombination (HR), nonhomologous end joining (NHEJ), and alternative nonhomologous end joining (A-NHEJ) were decreased (Schumacher et al. 2012). The increase in SSA was abolished when cells were infected with a viral mutant lacking UL12. Moreover, expression of UL12 alone caused an increase in SSA. UL12 and ICP 8 are reminiscent of the $\lambda$ phage recombination system that has been used as a tool for stimulating recombination-mediated genetic engineering in bacteria (Szczepanska 2009, and references therein). In addition, this system plays an important role in the production of viral DNA concatemers necessary for encapsidation and the production of infectious progeny (Lo Piano et al. 2011). The similarities between $\lambda$ and HSV DNA replication raise the possibility that concatemer formation during HSV infection involves recombination-dependent replication.

In addition to the UL12/ICP8 viral recombination system and the potential role of the SSA pathway during DNA replication, several other repair pathways have been implicated as required for efficient replication (Muylaert and Elias 2007, 2010; Muylaert et al. 2011). DNA ligase IV/XRCC4 have been reported to be important for efficient virus replication (Muylaert and Elias 2007) suggesting a beneficial role for NHEJ; however, in cells deficient for DNA-PK or Ku70, HSV-1 grows better than in their presence suggesting this conclusion may be oversimplified (Parkinson et al. 1999; K Mohni and S Weller, unpubl.). As described earlier, the interaction between the HSV-1 polymerase and HSV uracil-DNA-glycosylase (UL2) may indicate a role for base excision repair (Bogani and Boehmer 2008; Bogani et al. 2009, 2010). Recent reports that MSH2 and MLH1 are required for efficient replication of HSV-1 in normal human cells and are localized to viral replication compartments may indicate a role for mismatch repair in HSV replication (Mohni et al. 2011). Further investigation of the 
complex relationship between HSV and host repair/recombination pathways will be required to elucidate the role of various repair pathways in HSV DNA replication.

\section{FORMATION OF REPLICATION COMPARTMENTS, SITES OF VIRAL DNA SYNTHESIS}

HSV infection results in the dramatic reorganization of the infected cell nucleus involving relocalization of cellular proteins and the ordered assembly of replication compartments, large globular domains within the nucleus of infected cells in which gene expression, DNA replication, and cleavage and packaging are thought to occur (reviewed in Weller 2010; Ward and Weller 2011). Following entry of viral genomes into the nucleus, nucleoprotein complexes containing viral immediate early proteins ICP4 and ICP27 can be detected followed by the recruitment of ND10 proteins such as PML to sites adjacent to the ICP4/ICP27 nucleoprotein complexes (Everett et al. 2004; Everett and Murray 2005; Livingston et al. 2008). The recruitment of ND10 proteins to incoming viral genomes is thought to be repressive to viral gene expression, and these newly formed ND10-like foci are disrupted during lytic infection by a mechanism mediated by the HSV immediate early protein ICP0. The earliest stage prereplicative sites (ICP8 microfoci) contain ICP8, H/P, and UL9 and their formation requires the oligomerization of the immediate early protein ICP4 on viral genomes, the disruption of ND10-like structures, and ICP8 itself (Livingston et al. 2008, and other references). Recruitment of HSV Pol (UL30/42) requires the presence of an active primase (CarringtonLawrence and Weller 2003), and once this occurs, small replication compartments form, at which time ICP8 foci appear to merge with ICP4/27 foci (Livingston et al. 2008). Recent studies that monitor the location of incoming genomes have indicated that each RC forms from a single genome and that only a limited number of incoming genomes are actively expressed and go on to be replicated (Kobiler et al. 2011). Interestingly, the separation between different RCs is main- tained even when the nucleus is filled with viral DNA. Small RCs are known to grow in size, move, and coalesce. Chang et al. (2011) have recently reported that the movement of small RCs occurs by directed motion requiring actin and myosin. The late RCs appear to represent transcriptionally active RCs that have merged with nuclear speckles that promote export of late viral messenger RNAs (mRNAs).

\section{Efforts to Combat Viral Infections by Targeting DNA Replication}

Most of the antiviral agents developed to combat herpesvirus infections have targeted the viral polymerase. The mechanisms of action and resistance of these drugs, the most successful of which is acyclovir, have been reviewed (Weller and Coen 2006; Coen 2009). A new insight into the mechanism of the antiherpesvirus drug, foscarnet, has come from a crystallographic study suggesting that foscarnet stabilizes the untranslocated state of the polymerase, thereby stalling the enzyme (Zahn et al. 2011).

Despite its tremendous success, acyclovir has several drawbacks, including limited potency and efficacy, particularly against herpesviruses other than HSV and VZV, and the frequency at which immunocompromised patients develop resistant infections. This has led to the development of several new compounds, some of which have entered clinical trials. These new compounds include the nucleoside analogs valomaciclovir, a prodrug of a compound with a mechanism of action similar to acyclovir; FV100 , which is active against VZV, but may not be a polymerase inhibitor; CMX001, an orally available version of the approved anti-HCMV drug cidofovir; and cyclopropavir, which is active against HCMV and other $\beta$ herpesviruses (reviewed in Price and Prichard 2011). Development has also continued on compounds that target the UL5/UL8/UL52 H/P, which were reviewed previously (Weller and Coen 2006). In particular, AIC316 has completed a phase II trial. An interesting antiviral agent, maribavir, inhibits the HCMV protein kinase, UL97, which is important for viral DNA synthesis, particularly in nondividing cells, because it phosphorylates 
retinoblastoma protein family members (Wolf et al. 2001; Biron et al. 2002; Hume et al. 2008; Prichard et al. 2008; Kamil et al. 2009). This drug showed promise in phase II studies, but failed in phase III trials against HCMV infections in transplant patients (Marty et al. 2011). Thus, there is reason for optimism but also for caution regarding the prospects of these newer DNA replication inhibitors.

\section{CONCLUDING REMARKS}

In summary, HSV DNA replication is a complex process involving at least seven viral DNA replication proteins and possibly several host proteins as well. A major impediment to deeper understanding remains the lack of an in vitro system that reconstitutes origin-dependent replication. More incremental goals for the future are to determine the role of UL9 and other viral and cellular proteins in the initiation of replication, understand the mechanism of replication and the role of repair and recombination in the generation of replication products, and continue probing the structure, function, and functional interactions of the viral replication proteins. It is hoped that the results of these efforts will help us develop more effective strategies for antiviral therapy to prevent and treat all human herpesviruses.

\section{ACKNOWLEDGMENTS}

We thank members of our laboratories for helpful suggestions, especially Samantha Marques for help with Figure 1. This work is supported by National Institutes of Health (NIH) grants AI21747 and AI069136 to S.K.W., Connecticut stem cell research grant 09-SCA16 UCHC-34 to April Schumacher in the Weller laboratory, and NIH grants AI19838, AI26077, and AI26126 to D.M.C.

\section{REFERENCES}

Appleton BA, Loregian A, Filman DJ, Coen DM, Hogle JM. 2004. The cytomegalovirus DNA polymerase subunit UL44 forms a C clamp-shaped dimer. Mol Cell 15: $233-244$.
Appleton BA, Brooks J, Loregian A, Filman DJ, Coen DM, Hogle JM. 2006. The crystal structure of the cytomegalovirus DNA polymerase subunit with the C-terminus from the catalytic subunit: Differences in structure and function relative to unliganded UL44. J Biol Chem 281: 5224-5232.

Aslani A, Olsson M, Elias P. 2002. ATP-dependent unwinding of a minimal origin of DNA replication by the originbinding protein and the single-strand DNA-binding protein ICP8 from herpes simplex virus type I. J Biol Chem 277: 41204-41212.

Balasubramanian N, Bai P, Buchek G, Korza G, Weller SK. 2010. Physical interaction between the herpes simplex virus type 1 exonuclease, UL12, and the DNA doublestrand break-sensing MRN complex. J Virol 84: 1250412514.

Balliet JW, Schaffer PA. 2006. Point mutations in herpes simplex virus type 1 oriL, but not in oriS, reduce pathogenesis during acute infection of mice and impair reactivation from latency. J Virol 80: 440-450.

Baltz JL, Filman DJ, Ciustea M, Silverman JEY, Lautenschlager CL, Coen DM, Ricciardi RP, Hogle JM. 2009. The crystal structure of PF-8, the DNA polymerase accessory subunit from Kaposi's sarcoma-associated herpesvirus. J Virol 83: 12215-12228.

Biron KK, Harvey RJ, Chamberlain SC, Good SS, Smith AA Davis MG, Talarico CL, Ferris R, Dornsife RE, Stanat SC, et al. 2002. Potent and selective inhibition of human cytomegalovirus replication by 1263 W94, a benzimidazole L-riboside with a unique mode of action. Antimicrob Agents Chemother 46: 2365-2372.

Bogani F, Boehmer PE. 2008. The replicative DNA polymerase of herpes simplex virus 1 exhibits apurinic/apyrimidinic and 5' -deoxyribose phosphate lyase activities. Proc Natl Acad Sci 105: 11709-11714.

Bogani F, Chua CN, Boehmer PE. 2009. Reconstitution of uracil DNA glycosylase-initiated base excision repair in herpes simplex virus-1. J Biol Chem 284: 16784-16790.

Bogani F, Corredeira I, Fernandez V, Sattler U, Rutvisuttinunt W, Defais M, Boehmer PE. 2010. Association between the herpes simplex virus-1 DNA polymerase and uracil DNA glycosylase. J Biol Chem 285: 27664-27672.

Burch AD, Weller SK. 2005. Herpes simplex virus type 1 DNA polymerase requires the mammalian chaperone hsp90 for proper localization to the nucleus. J Virol 79: 10740-10749.

Carrington-Lawrence SD, Weller SK. 2003. Recruitment of polymerase to herpes simplex virus type 1 replication foci in cells expressing mutant primase (UL52) proteins. J Virol 77: 4237-4247.

Cavanaugh NA, Kuchta RD. 2009. Initiation of new DNA strands by the herpes simplex virus-1 primase-helicase complex and either herpes DNA polymerase or human DNA polymerase $\alpha$. J Biol Chem 284: 1523-1532.

Cavanaugh NA, Ramirez-Aguilar KA, Urban M, Kuchta RD. 2009. Herpes simplex virus-1 helicase-primase: Roles of each subunit in DNA binding and phosphodiester bond formation. Biochemistry 48: 10199-10207.

Chabaud S, Lambert H, Sasseville AM-J, Lavoie H, Guilbault C, Massie B, Landry J, Langelier Y. 2003. The R1 subunit of herpes simplex virus ribonucleotide reductase 
has chaperone-like activity similar to Hsp27. FEBS Lett 545: 213-218.

Chabaud S, Sasseville AM-J, Elahi SM, Caron A, Dufour F, Massie B, Langelier Y. 2007. The ribonucleotide reductase domain of the R1 subunit of herpes simplex virus type 2 ribonucleotide reductase is essential for $\mathrm{R} 1$ antiapoptotic function. J Gen Virol 88: 384-394.

Chang L, Godinez WJ, Kim IH, Tektonidis M, de Lanerolle P, Eils R, Rohr K, Knipe DM. 2011. Herpesviral replication compartments move and coalesce at nuclear speckles to enhance export of viral late mRNA. Proc Natl Acad Sci 108: E136-E144.

Chattopadhyay S, Weller SK. 2006. DNA binding activity of the herpes simplex virus type 1 origin binding protein, UL9, can be modulated by sequences in the $\mathrm{N}$ terminus: Correlation between transdominance and DNA binding. J Virol 80: 4491-4500.

Chattopadhyay S, Weller SK. 2007. Direct interaction between the $\mathrm{N}$ - and C-terminal portions of the herpes simplex virus type 1 origin binding protein UL9 implies the formation of a head-to-tail dimer. J Virol 81: 13659 13667.

Chattopadhyay S, Chen Y, Weller SK. 2006. The two helicases of herpes simplex virus type 1 (HSV-1). Front Biosci 11: 2213-2223.

Chen Y, Carrington-Lawrence SD, Bai P, Weller SK. 2005. Mutations in the putative zinc-binding motif of UL52 demonstrate a complex interdependence between the UL5 and UL52 subunits of the human herpes simplex virus type 1 helicase/primase complex. J Virol 79: 9088-9096.

Chen Y, Bai P, Mackay S, Korza G, Carson JH, Kuchta RD, Weller SK. 2011. Herpes simplex virus type 1 helicaseprimase: DNA binding and consequent protein oligomerization and primase activation. J Virol 85: 968-978.

Coen DM. 1996. Viral DNA polymerases. In DNA replication in eukaryotic cells (ed. DePamphilis ML), pp. 495-523. Cold Spring Harbor Laboratory Press, Cold Spring Harbor, NY.

Coen DM. 2009. Antiherpesviral DNA polymerase inhibitors. In Antiviral research: Strategies in antiviral drug discovery (ed. LaFemina R), pp. 1-18. ASM Press, Washington, DC.

Dodson MS, Lehman IR. 1991. Association of DNA helicase and primase activities with a subassembly of the herpes simplex virus 1 helicase-primase composed of the UL5 and UL52 gene products. Proc Natl Acad Sci 88: 1105-1109.

Dufour F, Sasseville A, Chabaud S. 2010. The ribonucleotide reductase $\mathrm{R} 1$ subunits of herpes simplex virus types 1 and 2 protect cells against TNF $\alpha$-and FasL-induced apoptosis by interacting with caspase-8. Apoptosis 16: 256-271.

Everett RD, Murray J. 2005. ND10 components relocate to sites associated with herpes simplex virus type 1 nucleoprotein complexes during virus infection. J Virol 79: 5078-5089.

Everett RD, Sourvinos G, Leiper C, Clements JB, Orr A. 2004. Formation of nuclear foci of the Herpes Simplex Virus Type 1 regulatory protein ICP4 at early times of infection: Localization, dynamics, recruitment of ICP27, and evidence for the de novo induction of ND10-like complexes. J Virol 78: 1903-1917.
Falkenberg M, Lehman IR, Elias P. 2000. Leading and lagging strand DNA synthesis in vitro by a reconstituted herpes simplex virus type 1 replisome. Proc Natl Acad Sci 97: 3896-3900.

Gao Y, Colletti K, Pari GS. 2008. Identification of human cytomegalovirus UL84 virus- and cell-encoded binding partners by using proteomics analysis. J Virol 82: 96-104.

Graves-Woodward KL, Gottlieb J, Challberg MD, Weller SK. 1997. Biochemical analyses of mutations in the HSV-1 helicase-primase that alter ATP hydrolysis, DNA unwinding, and coupling between hydrolysis and unwinding. J Biol Chem 272: 4623-4630.

Hume AJ, Finkel JS, Kamil JP, Coen DM, Culbertson MR, Kalejta RF. 2008. Phosphorylation of retinoblastoma protein by viral protein with cyclin-dependent kinase function. Science 320: 797-799.

Igarashi K, Fawl R, Roller RJ, Roizman B. 1993. Construction and properties of a recombinant herpes simplex virus 1 lacking both S-component origins of DNA synthesis. J Virol 67: 2123-2132.

Isler JA, Schaffer PA. 2001. Phosphorylation of the herpes sVirus type 1 origin binding protein. J Virol 75: 628-637.

Jiang C, Hwang YT, Randell JCW, Coen DM, Hwang CBC. 2007a. Mutations that decrease DNA binding of the processivity factor of the herpes simplex virus DNA polymerase reduce viral yield, alter the kinetics of viral DNA replication, and decrease fidelity of DNA replication. J Virol 81: 3495-3502.

Jiang C, Hwang YT, Wang G, Randell JCW, Coen DM, Hwang CBC. 2007b. Herpes simplex virus mutants with multiple substitutions affecting DNA binding of UL42 are impaired for viral replication and DNA synthesis. J Virol 81: 12077-12079.

Jiang C, Komazin-Meredith G, Tian W, Coen DM, Hwang CB-C. 2009. Mutations that increase DNA binding by the processivity factor of herpes simplex virus affect virus production and DNA replication fidelity. $J$ Virol 83: 7573-7580.

Jurak I, Kramer MF, Mellor JC, van Lint AL, Roth FP, Knipe DM, Coen DM. 2010. Numerous conserved and divergent microRNAs expressed by herpes simplex viruses 1 and 2. J Virol 84: 4659-4672.

Kamil JP, Hume AJ, Jurak I, Münger K, Kalejta RF, Coen DM. 2009. Human paillomavirus 16 E7 inactivator of retinoblastoma family proteins complements human cytomegalovirus lacking UL97 protein kinase. Proc Natl Acad Sci 106: 16823-16828.

Khalil MI, Arvin A, Jones J, Ruyechan WT. 2011. A sequence within the varicella-zoster virus (VZV) OriS is a negative regulator of DNA replication and is bound by a protein complex containing the VZV ORF29 protein. J Virol 85: 12188-12200.

Kim YE, Ahn JH. 2010. Role of the specific interaction of UL112-113 p84 with UL44 DNA polymerase processivity factor in promoting DNA replication of human cytomegalovirus. J Virol 84: 8409-8421.

Kobiler O, Brodersen P, Taylor MP, Ludmir EB, Enquist LW. 2011. Herpesvirus replication compartments originate with single incoming viral genomes. mBio 2: e00278-11.

Kochaniak AB, Habuchi S, Loparo JJ, Chang DJ, Cimprich KA, Walter JC, van Oijen AM. 2009. Proliferating cell 
nuclear antigen uses two distinct modes to move along DNA. J Biol Chem 284: 17700-17710.

Komazin-Meredith G, Mirchev R, Golan DE, van Oijen AM, Coen DM. 2008a. Hopping of a processivity factor on DNA revealed by single-molecule assays of diffusion. Proc Natl Acad Sci 105: 10721-10726.

Komazin-Meredith G, Petrella RJ, Santos WL, Filman DJ, Hogle JM, Verdine GL, Karplus M, Coen DM. 2008b. The human cytomegalovirus UL44 C clamp wraps around DNA. Structure 16: 1214-1225.

Komazin-Meredith G, Santos WL, Filman DJ, Hogle JM Verdine GL, Coen DM. 2008c. The positively charged surface of herpes simplex virus UL42 mediates DNA binding. J Biol Chem 283: 6154-6161.

Link MA, Silva LA, Schaffer PA. 2007. Cathepsin B mediates cleavage of herpes simplex virus type 1 origin binding protein (OBP) to yield OBPC-1, and cleavage is dependent upon viral DNA replication. J Virol 81: 9175-9182.

Liu S, Knafels JD, Chang JS, Waszak GA, Baldwin ET, Deibel MR Jr, Thomsen DR, Homa FL, Wells PA, Tory MC, et al. 2006. Crystal structure of the herpes simplex virus 1 DNA polymerase. J Biol Chem 281: 18193-18200.

Livingston C, Kyratsous C. 2011. Molecular chaperones and alphaherpesvirus infection. In Alphaherpesviruses: Molecular virology (ed. Weller SK), Chap. 14, pp. 237-256. Caister Academic, Norfolk, UK.

Livingston CM, DeLuca NA, Wilkinson DE, Weller SK. 2008. Oligomerization of ICP4 and rearrangement of heat shock proteins may be important for herpes simplex virus type 1 prereplicative site formation. J Virol 82: 6324-6336.

Lo Piano A, Martinez-Jimenez MI, Zecchi L, Ayora S. 2011. Recombination-dependent concatemeric viral DNA replication. Virus Res 160: 1-14.

Macao B, Olsson M, Elias P. 2004. Functional properties of the herpes simplex virus type I origin-binding protein are controlled by precise interactions with the activated form of the origin of DNA replication. J Biochem 279: 2921129217.

Maga G, Hubscher U. 2003. Proliferating cell nuclear antigen (PCNA): A dancer with many partners. J Cell Sci 116: 3051-3060.

Makhov AM, Boehmer PE, Lehman IR, Griffith JD. 1996. The herpes simplex virus type 1 origin-binding protein carries out origin specific DNA unwinding and forms stem-loop structures. EMBO J 15: 1742-1750.

Makhov AM, Lee SS, Lehman IR, Griffith JD. 2003. Originspecific unwinding of herpes simplex virus 1 DNA by the viral UL9 and ICP8 proteins: Visualization of a specific preunwinding complex. Proc Natl Acad Sci 100: 898-903.

Makhov AM, Sen A, Yu X, Simon MN, Griffith JD, Egelman EH. 2009. The bipolar filaments formed by herpes simplex virus type $1 \mathrm{SSB} /$ recombination protein (ICP8) suggest a mechanism for DNA annealing. J Mol Biol 386: 273-279.

Maluf NK, Fischer CJ, Lohman TM. 2003. A dimer of Escherichia coli UvrD is the active form of the helicase in vitro. J Mol Biol 325: 913-935.

Manolaridis I, Mumtsidu E, Konarev P, Makhov AM, Fullerton SW, Sinz A, Kalkhof S, McGeehan JE, Cary PD, Griffith JD, et al. 2009. Structural and biophysical char- acterization of the proteins interacting with the herpes simplex virus 1 origin of replication. $J$ Biochem 284: $16343-16353$.

Mapelli M, Muhleisen M, Persico G, van Der Zandt H, Tucker PA. 2000. The 60-residue C-terminal region of the single-stranded DNA binding protein of herpes simplex virus type 1 is required for cooperative DNA binding. J Virol 74: 8812-8822.

Mapelli M, Panjikar S, Tucker PA. 2005. The crystal structure of the herpes simplex virus 1 ssDNA-binding protein suggests the structural basis for flexible, cooperative single-stranded DNA binding. J Biol Chem 280: 2990-2997.

Marintcheva B, Weller SK. 2003a. Existence of transdominant and potentiating mutants of UL9, the herpes simplex virus type 1 origin-binding protein, suggests that levels of UL9 protein may be regulated during infection. J Virol 77: 9639-9651.

Marintcheva B, Weller SK. 2003b. Helicase motif Ia is involved in single-strand DNA-binding and helicase activities of the herpes simplex virus type 1 origin-binding protein, UL9. J Virol 77: 2477-2488.

Marsden HS, Cross AM, Francis GJ, Patel AH, MacEachran K, Murphy M, McVey G, Haydon D, Abbotts A, Stow ND. 1996. The herpes simplex virus type 1 UL8 protein influences the intracellular localization of the UL52 but not the ICP8 or POL replication proteins in virus-infected cells. J Gen Virol 77: 2241-2249.

Marty FM, Ljungman P, Papanicolaou GA, Winston DJ, Chemaly RF, Strasfeld L, Young JA, Rodriguez T, Maertens J, Schmitt M, et al. 2011. Maribavir prophylaxis for prevention of cytomegalovirus disease in recipients of allogeneic stem-cell transplants: A phase 3, double-blind, placebo-controlled, randomised trial. Lancet Infect Dis 11: 284-292.

Mohni KN, Mastrocola AS, Bai P, Weller SK, Heinen CD. 2011. DNA mismatch repair proteins are required for efficient herpes simplex virus 1 replication. J Virol 85: 12241-12253.

Moldovan GL, Pfander B, Jentsch S. 2007. PCNA, the maestro of the replication fork. Cell 129: 665-679.

Mullaney J, Moss HW, McGeoch DJ. 1989. Gene UL2 of herpes simplex virus type 1 encodes a uracil-DNA glycosylase. J Gen Virol 70: 449-454.

Murayama K, Nakayama S, Kato-Murayama M, Akasaka R, Ohbayshi N, Kamewari-Hayami Y, Terada T, Shirouzu M, Tsurumi T, Yokoyama S. 2009. Crystal structure of Epstein-Barr virus DNA polymerase processivity factor BMRF1. J Biol Chem 284: 35896-35905.

Muylaert I, Elias P. 2007. Knockdown of DNA ligase IV/ XRCC4 by RNA interference inhibits herpes simplex virus type I DNA replication. J Biochem 282: 10865-10872.

Muylaert I, Elias P. 2010. Contributions of nucleotide excision repair, DNA polymerase $\eta$, and homologous recombination to replication of UV-irradiated herpes simplex virus type 1. J Biol Chem 285: 13761-13768.

Muylaert I, Tang K-W, Elias P. 2011. Replication and recombination of herpes simplex virus DNA. J Biol Chem 286: 15619-15624.

Niedziela-Majka A, Chesnik MA, Tomko EJ, Lohman TM. 2007. Bacillus stearothermophilus PcrA monomer is a single-stranded DNA translocase but not a processive helicase in vitro. J Biol Chem 282: 27076-27085. 
S.K. Weller and D.M. Coen

Olsson M, Tang K-W, Persson C, Wilhelmsson LM, Billeter M, Elias P. 2009. Stepwise evolution of the herpes simplex virus origin binding protein and origin of replication. J Biochem 284: 16246-16255.

Parkinson J, Lees-Miller SP, Everett RD. 1999. Herpes simplex virus type 1 immediate-early protein vmw110 in duces the proteasome-dependent degradation of the catalytic subunit of DNA-dependent protein kinase. J Virol 73: $650-657$.

Peng H, Nogueira ML, Vogel JL, Kristie TM. 2010. Transcriptional coactivator HCF-1 couples the histone chaperone Asflb to HSV-1 DNA replication compartments. Proc Natl Acad Sci 107: 2461-2466.

Polvino-Bodnar M, Orberg PK, Schaffer PA. 1987. Herpes simplex virus type 1 oriL is not required for virus replication or for the establishment and reactivation of latent infection in mice. J Virol 61: 3528-3535.

Price NB, Prichard MN. 2011. Progress in the development of new therapies for herpesvirus infections. Curr Opin Virol 1: 548-554.

Prichard MN, Sztul E, Daily SL, Perry AL, Frederick SL, Gil RB, Hartline CB, Streblow DN, Varnum SM, Smith RD, et al. 2008. Human cytomegalovirus UL97 kinase is required for the hyperphosphorylation of retinoblastoma protein and inhibits the formation of nuclear aggresomes. J Virol 82: 5054-5067.

Pyles RB, Thompson RL. 1994. Evidence that the herpes simplex virus type 1 uracil DNA glycosylase is required for efficient viral replication and latency in the murine nervous system. J Virol 68: 4963-4972.

Randell JCW, Komazin G, Jiang C, Hwang CBC, Coen DM. 2005. Effects of substitutions of arginine residues on the basic surface of herpes simplex virus UL42 support a role for DNA binding in processive DNA synthesis. J Virol 79: 12025-12034.

Schumacher AJ, Mohni KN, Kan Y, Hendrickson E, Stark JM, Weller SK. 2012. The HSV-1 exonuclease, UL12, stimulates recombination by a single strand annealing mechanism. PLoS Pathog (under revision).

Stengel G, Kuchta RD. 2011. Coordinated leading and lagging strand DNA synthesis by using the herpes simplex virus 1 replication complex and minicircle DNA templates. J Virol 85: 957-967.

Strang BL, Coen DM. 2010. Interaction of the human cytomegalovirus uracil DNA glycosylase UL114 with the viral DNA polymerase catalytic subunit UL54. J Gen Virol 91: 2029-2033.

Strang BL, Boulant S, Coen DM. 2010a. Nucleolin associates with the human cytomegalovirus DNA polymerase ac- cessory subunit UL44 and is necessary for efficient viral replication. J Virol 84: 1771-1784.

Strang BL, Geballe AP, Coen DM. 2010b. Association of human cytomegalovirus proteins IRS1 and TRS1 with the viral DNA polymerase accessory subunit UL44. J Gen Virol 91: 2167-2175.

Strang BL, Boulant S, Kirchhausen T, Coen DM. 2012. Host cell nucleolin is required to maintain the architecture of human cytomegalovirus replication compartments. mBio 3: e00301-e00311.

Swan MK, Johnson RE, Prakash L, Prakash S, Aggarwal AK. 2009. Structural basis of high-fidelity DNA synthesis by yeast DNA polymerase delta. Nat Struct Mol Biol 16: 979-986.

Szczepanska AK. 2009. Bacteriophage-encoded functions engaged in initiation of homologous recombination events. Crit Rev Microbiol 35: 197-220.

Walsh D, Mohr I. 2006. Assembly of an active translation initiation factor complex by a viral protein. Genes Dev 20: 461-472.

Ward S, Weller S. 2011. HSV-1 DNA replication. In Alphaherpesviruses: Molecular virology (ed. Weller SK), Chap. 6, pp. 89-112. Caister Academic, Norfolk, UK.

Weitzman M, Weller S. 2011. Interactions between HSV-1 and the DNA damage response. In Alphaherpesviruses: Molecular virology (ed. Weller SK), Chap. 15, pp. 257268. Caister Academic, Norfolk, UK.

Weller SK. 2010. Herpes simplex virus reorganizes the cellular DNA repair and protein quality control machinery. PLoS Pathog 6: e1001105.

Weller SK, Coen DM. 2006. Herpes simplex virus. In DNA replication and human disease (ed. DePamphilis ML), pp. 663-686. Cold Spring Harbor Laboratory Press, Cold Spring Harbor, NY.

Wolf DG, Courcelle CT, Prichard MN, Mocarski ES. 2001. Distinct and separate roles for herpesvirus-conserved UL97 kinase in cytomegalovirus DNA synthesis and encapsidation. Proc Natl Acad Sci 98: 1895-1900.

Yang Y, Dou SX, Ren H, Wang PY, Zhang XD, Qian M, Pan BY, Xi XG. 2008. Evidence for a functional dimeric form of the PcrA helicase in DNA unwinding. Nucl Acids Res 36: 1976-1989.

Zahn KE, Tchesnokov EP, Gotte M, Doublie S. 2011. Phosphonoformic acid inhibits viral replication by trapping the closed form of the DNA polymerase. J Biol Chem 286: $25246-25255$.

Zhu Y, Wu X, Cardoso MC, Parris DS. 2010. Processing of lagging-strand intermediates in vitro by herpes simplex virus type 1 DNA polymerase. J Virol 84: 7459-7472. 


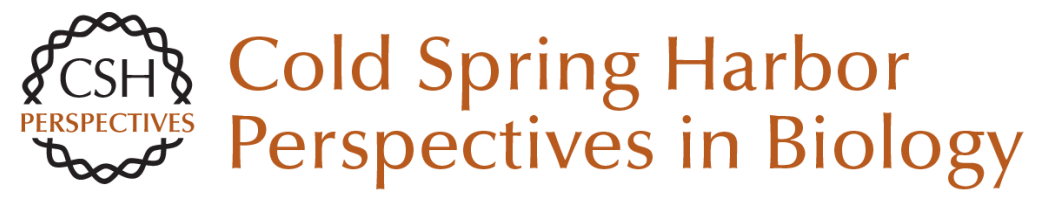

\section{Herpes Simplex Viruses: Mechanisms of DNA Replication}

Sandra K. Weller and Donald M. Coen

Cold Spring Harb Perspect Biol 2012; doi: 10.1101/cshperspect.a013011

\section{Subject Collection DNA Replication}

\section{Replication of Epstein-Barr Viral DNA} Wolfgang Hammerschmidt and Bill Sugden

Replication Proteins and Human Disease Andrew P. Jackson, Ronald A. Laskey and Nicholas Coleman

Break-Induced DNA Replication Ranjith P. Anand, Susan T. Lovett and James E. Haber

Regulating DNA Replication in Eukarya Khalid Siddiqui, Kin Fan On and John F.X. Diffley

Archaeology of Eukaryotic DNA Replication Kira S. Makarova and Eugene V. Koonin

Translesion DNA Polymerases Myron F. Goodman and Roger Woodgate

Human Papillomavirus Infections: Warts or Cancer?

Louise T. Chow and Thomas R. Broker

\section{Chromatin and DNA Replication}

David M. MacAlpine and Geneviève Almouzni

\section{Endoreplication \\ Norman Zielke, Bruce A. Edgar and Melvin L. DePamphilis}

Replication-Fork Dynamics

Karl E. Duderstadt, Rodrigo Reyes-Lamothe, Antoine M. van Oijen, et al.

Helicase Activation and Establishment of Replication Forks at Chromosomal Origins of Replication Seiji Tanaka and Hiroyuki Araki

\section{Poxvirus DNA Replication} Bernard Moss

The Minichromosome Maintenance Replicative Helicase Stephen D. Bell and Michael R. Botchan

DNA Replication Origins Alan C. Leonard and Marcel Méchali

Principles and Concepts of DNA Replication in

Bacteria, Archaea, and Eukarya Michael O'Donnell, Lance Langston and Bruce Stillman

DNA Replication Timing Nicholas Rhind and David M. Gilbert

For additional articles in this collection, see http://cshperspectives.cshlp.org/cgi/collection/

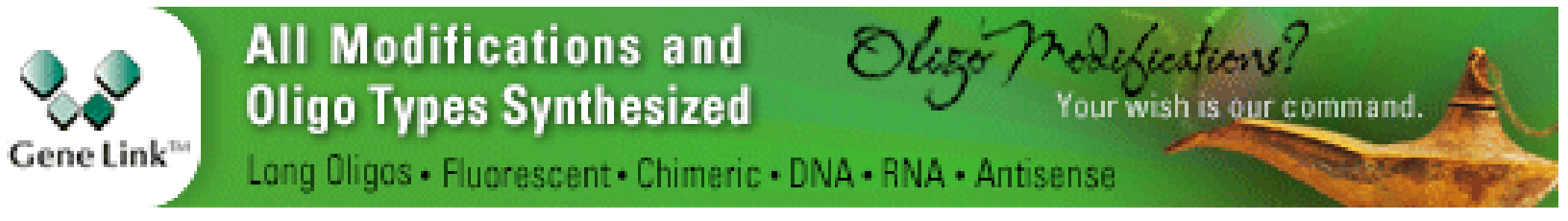

